\title{
EL ÉXITO DE UNA «MÉTHODE PRATIQUE» DE LA CASA LAROUSSE: L'ESPAGNOL COMMERCIAL (1890-1923) DE E. CONTAMINE DE LATOUR
}

\author{
MARÍA ÁNGELES GARcía ARANDA \\ Universidad Complutense de Madrid*
}

\section{Resumen}

En el siglo XIX, fruto de las circunstancias políticas, económicas y sociales que marcaron Europa, aparecieron diversos materiales de enseñanza de español comercial en forma de artes o manuales de correspondencia.

Este artículo se ocupa de L'espagnol commercial de Emmanuel Contamine de Latour (París, Larousse, de 1890 a 1923, 11. a edición de la obra), con el objetivo de contribuir a la historia de unos materiales poco conocidos pero muy rentables, a su origen, al contexto en que aparecieron, a las necesidades que satisfacían, a la lengua que reflejaban o a la metodología empleada.

Palabras clave: español, fines específicos, comercio, siglo XIX, Contamine de LatourLarousse.

THE SUCCES OF A «MÉTHODE PRATIQUE» OF THE LAROUSSE HOUSE: L'ESPAGNOL COMMERCIAL (1890-1923) BY E. CONTAMINE DE LATOUR

\section{Abstract}

In the nineteenth century, the political, economic and social circumstances that marked Europe determined the publication of various teaching materials of commercial Spanish appeared in the form of correspondence arts or manuals.

This paper deals with L'espagnol commercial by Emmanuel Contamine de Latour (Paris, Larousse, from 1890 to 1923,11 th edition), with the aim of contributing to the

\footnotetext{
" Este trabajo se enmarca dentro del Proyecto de Investigación «Biblioteca Virtual de la Filología Española. Fase III: nuevas bibliotecas y nuevos registros. Información bibliográfica. Difusión de resultados» (FFI2017-82437-P).
} 
history of some little-known materials but very profitable, to their origin, to the context in which they appeared, to the needs they satisfied, to the language they reflected or to the methodology used.

Keywords: Spanish, specific purposes, business, Nineteenth century, Contamine de Latour-Larousse.

\section{INTRODUCCIÓN}

Las circunstancias políticas, económicas y sociales que trajo consigo el siglo XIX produjeron un aumento considerable en la edición y publicación de manuales de enseñanza de español como segunda lengua en Francia, lo que, además, se vio favorecido por los beneficios económicos que proporcionaba la industria del libro y por «l'introduction des langues vivantes dans les programmes de l'enseignement secondaire, à titre facultatif en 1829, puis comme discipline obligatoire à partir de 1838» (Choppin, 1995: 19). Los textos, reeditados y versionados una y otra vez, de Sobrino, de Gattel, de Núñez de Taboada, de Josse, de Sotos Ochando, de Salvá, de Gómez Hermosilla y de Corona Bustamante, y los métodos de Ollendorf, Ahn, Berlitz, Robertson y Hossfeld son buena muestra de ello (Choppin, 1992; Esparza y Niederehe, 2015; Sánchez Pérez, 1992).

Pero, junto a la lengua general, era necesario atender también otras necesidades surgidas del contacto entre las dos naciones: el aumento de las transacciones en Europa y entre Europa y América, la industrialización, la revolución de los transportes, el incremento de las comunicaciones, el desarrollo de la banca y la creciente demanda de materias primas y manufacturas que se producen a lo largo del siglo XIX suponen un crecimiento considerable para el comercio que exige profesionales bien formados tanto en el comercio como en las lenguas de los países con las que tenían que llevarse a cabo las relaciones comerciales.

Aparecen así los primeros centros de enseñanza especializada ${ }^{1}$, se incluyen materias específicas en los planes de estudio de las escuelas secundarias y se publican los primeros textos, a imitación de los que se

${ }^{1}$ En 1819, por ejemplo, se funda la École Supériure de Commerce de París; en 1866, la de Mulhouse; en 1871, la de Le Havre; en 1872, la de Lyon y la de Marseille; en 1874, la de Burdeos; en 1892, la de Lille; en 1897, la de Montpellier; en 1881, la École des Hautes Études 
habían compuesto para el inglés, destinados exclusivamente al español especializado, técnico o comercial (Choppin, 1995; García Aranda, 2012a, 2012b y 2019). La mayoría de ellos profundiza en el léxico y en la correspondencia comercial (para otros fines ya existían diccionarios, gramáticas y manuales varios), pues el lenguaje de los negocios exige conocer el vocabulario de este tecnolecto y la forma de las cartas y escritos que para esta actividad se redactan, así como las diferencias que existen entre ellos, ya que no es lo mismo componer una circular, un ofrecimiento de servicio o una operación comercial.

El desarrollo de estos materiales justifica el análisis de L'espagnol commercialde Emmanuel Contamine de Latour, un método que, a partir de varias fuentes, se define como "pratique commerciale et technique permettant aux commerçants, aux industriels et aux agriculteurs de se servir de la langue en peu de temps» (pág. 5).

En las páginas que siguen se presenta un análisis de la estructura y del contenido de L'espagnol commercial, con el objetivo de contribuir a la historia de unos materiales poco conocidos pero muy rentables, a su origen, al contexto en que aparecieron, a la labor de editores e impresores, a las necesidades que satisfacían, a la lengua que reflejaban o a la metodología empleada.

\section{L'ESPAGNOL COMMERCIAL DE E. CONTAMINE DE LATOUR}

En 1890 la Librería Larousse publica en París L'espagnol commercial. Nouvelle méthode de correspondance expliquant les expresions, termes, formules de commerce de bourse, de change, etc. suivi d'un Vocabulaire espagnol-français et français-espagnol et d'une carte commercial des pays de langue espagnole ${ }^{2}$, obra de poco más de doscientas páginas firmada por, el traductor miembro de las Academias Reales de Sevilla y Barcelona y profesor en la École des Hautes Études commerciales, en la

Commerciales de París y en 1884, el Institut Commercial de París. Véase el capítulo sobre la historia de los estudios mercantiles en España de Fernández Aguado (1997: 1-60).

${ }^{2}$ Utilizo el ejemplar de la Universidad de Toronto (con signatura LaS.GrC7592e) como fuente primaria para este trabajo, por lo que indicaremos únicamente el número de página entre paréntesis. Hay un ejemplar en la Biblioteca de la Real Academia Española fechado en 1884, aunque es una «fecha aproximada por otras obras del autor». 
École municipale Arago, en la École commercial y en el Cercle Nationale des Armées de terre et de mer y examinador en el Institut commercial, Emmanuel Contamine de Latour ${ }^{3}$. Debió tener éxito el librito, pues la casa editorial Larousse se benefició de él desde 1890 hasta 1923, año en que ve la luz la 11 . $^{\mathrm{a}}$ edición. El objetivo del manual, tal y como se expone en la introducción, es claro:

l'utilité de la connaissance de la langue castillane nous est prouvée par la fréquentation toujours croissante des cours d'espagnol professés dans les écoles de commerce et dans les cours des associations d'enseigment technique [...]. Jusqu'à ce jour il manquait, malheureusement, à l'enseignement de l'espagnol une méthode commerciale et technique permettant aux commerçants, aux industriels et aux agriculteurs de se servir de la langue en peu temps; les livres mis jusqu'à présent entre les mains des élèves et des auditeurs ne contenaient que des phrases banales et sans aucune utilité pour les affaires; ils étaient, en outre, presque tous défectueux tant au point de vue du plan qu'à celui de la grammaire (5).

Para resolver estas carencias, Contamine de Latour y la editorial Larousse $^{4}$ preparan un método que aúna gramática con frases comerciales para traducir, diálogos sobre temática técnica y muestras de diversos géneros comerciales.

\footnotetext{
${ }^{3}$ Es, además, autor de La literatura siciliana (ensayo sobre el folk-lore)(Léchenet, París, 1894), de los Chants nationaux de l'Amérique latine (Carpentier, Montdidier, 1912), de El ejército brasileño (Arias, Madrid, 1914), de los Apuntes históricos (1914-1916) (Arias, Madrid, 1916) y colaborador del Primer libro de francés. Método intuitivo ilustrado de Marchand (1922). Fue estudioso, según consta en el Boletín de la Real Academia Gallega (1929, tomo 19, pág. 103), "de los asuntos gallegos y de la vida española e hispano-americana, desde hace medio siglo sostenía relación frecuente y directa con las más relevantes personalidades de Galicia; en muchas ocasiones pronunció conferencias y escribió trabajos dedicados a divulgar en Francia las bellezas y atractivos de nuestro país y la intensidad de su cultura».

${ }^{4}$ Se puede leer en la introducción, en este sentido, que «les éditeurs comblent une lacune et rendent un véritable service aux nombreuses personnes qui en France se livrent au commerce avec l'Amérique espagnole» (5).
} 


\section{CONTENIDO Y ESTRUCTURA DE L'ESPAGNOL COMMERCIAL}

L'espagnol commercial, a diferencia de otros manuales que separan nítidamente los contenidos lingüísticos de los comerciales, combina gramática, diálogos, cartas y modelos de escritos de interés para los destinatarios de la obra; así, en ciento ochenta y seis lecciones se presenta «la grammaire aussi simple et aussi pratique que possible, en y donnant les règles les plus indispensables pour parler et écrire commercialement en peu de temps» (5) acompañada de "une série de thèmes et de versions, portant tous sur la langage commercial et industrial» (5). Esto es, L'espagnol commercial presenta una parte del discurso, clase de palabra o categoría gramatical, sus formas y principales usos, algunos ejemplos de frases y, en último lugar, ejercicios o prácticas de traducción, tanto directa como inversa. Las lecciones gramaticales se completan con diálogos y textos comerciales.

Se trata, pues, de una obra que reúne los rudimentos de la lengua española y los principales documentos para desenvolverse en el ámbito comercial. Metodológicamente, L'espagnol commercial integra, como muchos otros manuales, los principios del método tradicional, de la traducción interlineal ${ }^{5}$, de los diálogos y del método conversacional, si bien su originalidad radica en su aplicación al comercio gracias a los ejemplos y a las situaciones de uso que reproduce ${ }^{6}$ (Gallardo Barbarroja, 2003; García Aranda 2012a, 2012b y 2019; Sánchez Pérez, 1992). Al igual que otros autores y editores de la centuria, Contamine de Latour y Larousse, preocupados por la escasa eficacia de los excesivamente teóricos manuales de enseñanza, anteponen la práctica y el uso para que sus alumnos aprendan a escribir y hablar el español comercial:

Le livre que nous offrons aujourd'hui au public n'est pas un livre savant, c'est une méthode pratique, et nous sommes persuadés que l'étude attentive de l'Espagnol commercial, faite sous la direction

\footnotetext{
${ }^{5}$ Así justifica Contamine de Latour la presencia, por otro lado abundante en algunos métodos de enseñanza compuestos en esta misma centuria, de la traducción interlineal: "permet de se bien rendre compte du mécanisme de la construction et de la signification des mots» (6).

${ }^{6}$ Podría resultar un buen ejemplo del eclecticismo que impera en la centuria en muchos manuales de enseñanza de segundas lenguas (Gallardo Barbarroja, 2002: 93).
} 
d'un bon maître, permettra aux personnes qui se destinent à la carrière commerciale de lire et d'écrire l'espagnol, et même de le parler. C'est à ce double point de vue de la conversation et de la correspondance que sont placés tous nos exercices; c'est pourquoi, nous le répétons, notre méthode n'est point savante mais pratique, car tous les mots, toutes les phrases sont absolument nécessaires et indipensables au négociant (6).

\subsection{Contenidos lingüísticos}

\subsubsection{Gramática}

El contenido gramatical de L'espagnol commercial incluye unas notas sobre la pronunciación y el acento en español y una sucinta caracterización de las clases de palabras ${ }^{7}$.

Las «Notions générales» que inician el volumen ofrecen, a partir de la relación grafía-sonido y teniendo en cuenta los sistemas fonológicos del francés, del inglés y del español, una explicación sobre los sonidos españoles inexistentes en francés y una breve descripción de las particularidades acentuales de nuestra lengua ${ }^{8}$.

Las categorías gramaticales, por su parte, son presentadas de forma sencilla, sin aparato teórico y siempre en función de su traducción o equivalencia en francés. Así, repasa, a partir de reglas redactadas escuetamente, las formas, usos, reglas y principales funciones del artículo, del sustantivo, de los adjetivos, de los sufijos aumentativos y diminutivos, de los pronombres personales, posesivos, demostrativos, relativos, interrogativos e indefinidos, de la forma de tratamiento usted propia del «style

${ }^{7}$ La única lección del manual que no tiene contenido gramatical sino léxico es la dedicada a fulano, zutano y mengano, palabras «qui signifient 'un tel', employés pour former certaines locutions curieuses», como fulano ha venido a verle, fulano y zutano estaban ayer en la Bolsa o el sr. Robilla está ocupado, habla con fulano y mengano (64).

${ }^{8}$ Por ejemplo, señala que la pronunciación de la española $u$ es como ou francés (como velar y no como palatal redondeada), que la e se articula como la é cerrada del francés, que ch es "comme tch» (solución para una articulación africada como la española y no fricativa como la francesa), que el velar fricativo sordo «n'existe pas en français» o que el acento español implica que la sílaba es "plus longue», palabras que parecen aludir a la cantidad o mayor duración de la sílaba tónica, esto es, un acento que lleva aparejada diferente duración, y ofrece, para facilitar la pronunciación correcta, las reglas de acentuación en español (11-13). 
élevé» ${ }^{9}$, del pronombre francés $o{ }^{10}$, de los verbos -esta es, sin duda alguna, la categoría gramatical mejor tratada, dado que Contamine de Latour (13) se afana en presentar «les modèles des verbes d'une façon saisissante et qui les rend fáciles à retenir» acompañados de «tableaux complets de chaque conjugaison, que l'élève pourra consulter au besoin»-, de los adverbios, de las preposiciones y locuciones prepositivas ${ }^{11}$ y de la equivalencia en español de los présentatifs voici y voilà ${ }^{12}$.

Las lecciones gramaticales son un compendio breve, incompleto, insuficiente, poco original, sin demasiado aparato teórico y destinado únicamente a facilitar el aprendizaje de la lengua española, por lo que se simplifican al máximo su fonética, su morfología y su sintaxis, dejando el resto al criterio del profesor. Se entiende, ahora sí, que en las páginas preliminares Contamine de Latour y Larousse lo califiquen como «une méthode pratique» que necesita de «la direction d'un bon maître» si comerciantes y vendedores quieren llegar a leer, escribir, y hablar bien en español.

\subsubsection{Las prácticas de traducción}

Tras cada una de las lecciones gramaticales, incluye diferentes ejercicios para practicar la lengua comercial e industrial. Estas prácticas o modelos de lenguaje comercial pueden estar constituidos por frases simples en español o francés para ejercitarse tanto en la traducción directa como en la inversa, cartas comerciales con traducción interlineal y diálogos.

${ }^{9}$ Aclara que vous y usted no siempre se corresponden, «il y a des cas où les deux mots, usted et vous, ne se correspondent pas» (101), pues el segundo, en su forma $V$. o Vs., es una abreviación de vuestra merced, vuestras mercedes, por lo que hay que prestar atención en la traducción.

${ }^{10}$ Dice sobre él: «on peu le traduire par se avec le verbe à la $3^{\mathrm{a}}$ personne du singulier [...], il peut souvent être supprimé et rendu, quand le sens de la phrase le permet, par la $1^{\text {ra }}$ personne du pluriel sans pronom [...], quand il parait deux fois dans la même phrase, on peut le traduire par uno, la première fois seulement» (64).

${ }^{11}$ Junto a la nómina de preposiciones y locuciones prepositivas, hay unas líneas para señalar que chez no existe en español y debe traducirse por en casa de... y que por-par «s'emploie à la place de para, pour, quand elle désigne un laps de temps; quand elle insique un échange, un équivalent ou une valeur; quand il s'agit de faire quelque chose à la place de quelqu'un; pour indiquer qu'une opinion est bonne ou mauvaise, ou qu'une chose est à faire» (111).

12 Estas formas «n'ont pas d'équivalents en espagnol; on les traduit par une locution composée du verbe haber et des adverbes aquí, alli» (101). 
Las prácticas de traducción, presentes en la historia de los manuales de enseñanza de segundas lenguas desde antiguo (Sánchez Pérez, 1992), están encaminadas a familiarizarse con la lengua española y el discurso comercial. Las frases, siempre de temática comercial, presentan una gradación de las más fáciles y sencillas de las primeras lecciones a las más complicadas de las últimas; así, por ejemplo, en los capítulos sobre los verbos auxiliares o sobre el sustantivo, el autor propone practicar con oraciones como: He comprado un paraguas, El caballero llegó ayer de París, Mi cliente llegó ayer, Un monsieur est arrivé, Ils ont souvent vendu des montres o Nous avons envoyé la lettre, mientras que los apartados que cierran la obra sobre los verbos irregulares o las categorías invariables están acompañados de estructuras como Hoy le mando a V. su último pedido menos los juguetes de plomo que saldrán por el vapor del ocho del mes que viene; Con motivo de la muerte del señor $X . . .$, la antigua sociedad $X$. y $C^{a}$ queda disuelta, la nueva sociedad continuará con la casa, bajo la razón social de Alejandro hermanos; Quand vous irez à Lyon, je vous recommande mon ami $X$., il a une maison de soieries et il a également à Saint-Étienne une fabrique de rubans soie et soie et coton o Le paquebot "Ciudad Condal» est arrivé des Antilles avec un chargement de sucre, cacao et tabac, il partira dans huit jours et emportera votre envoie d'articles pour hommes, sauf les chemises, qui ne partiront que le mois prochain.

De la misma manera, las cartas comerciales con la traducción interlineal, con amplia tradición también en la historia de la enseñanza de segundas lenguas ${ }^{13}$, están presentadas en función de su dificultad: las primeras son «lettres faciles» $\mathrm{y}$, a partir del verbo, se encuentran modelos de «lettre accusant réception de marchandises», "lettre promettant de s'occuper d'une commande reçue», «lettre demandant de plus amples renseignements», «lettre offrant porcelaines, etc., du Japon», «avis de vente aux enchères de bois de teinture», «lettre des colonies, signalant le genre de produit demandé», «le commerce de la pelleterie: commissionnaire ne peut exécuter ordre au prix fixé» $\mathrm{y}$ «fabricant menace de poursuivre contrefacteurs».

${ }^{13}$ Era habitual considerar, siguiendo a los clásicos, que las cartas son una conversación escrita (Castillo Gómez, 2006 y 2011, Petrucci, 2008) y, por tanto, una buena forma de aprender una lengua extranjera. 
Las cartas comerciales y las frases propuestas como ejercicios de traducción muestran una serie de rasgos «empleados tradicionalmente en la redacción comercial para atraer la atención del receptor o destinatario del escrito» que incluyen fórmulas fijas que «tienen que ser consideradas para su análisis desde una perspectiva pragmática, puesto que su significado estará en todo momento condicionado por el contexto socio-profesional en el que se encuentran insertas» (Gómez de Enterría, 1998: 389), y que no se diferencian de las compuestas en otros lugares durante este periodo $^{14}$.

Suelen además presentar una estructura con fórmulas anticuadas: encabezamiento con la ciudad, fecha y nombre del emisor/remitente, el saludo, el cuerpo de la carta y una forma abreviada de despedida. Los saludos más habituales en L'espagnol commercial, que apenas han sufrido modificaciones con el paso del tiempo, son o bien fórmulas como muy señores nuestros, esto es, «indicadores de respecto de distancia» o bien mi estimado amigo, estimado Sr. Domínguez, es decir, «indicadores de deferencia y afecto» (Gómez de Enterría, 2003: 320). Por el contrario, las fórmulas habituales de despedida, S.S.Q.B.S.M. (seguro servidor que besa su mano), su servidor, quedamos de ustedes atentos servidores, son «deudoras de la centuria a la que pertenecen. Están situadas dentro de una visión más clásica de la cortesía que refleja una organización social ya desfasada» (Gómez de Enterría, 2003: 320).

En el cuerpo de la carta, las fórmulas lingüísticas y pragmáticas se ponen al servicio de las intenciones de cada uno de los veintidós actos de habla: a veces han de exigir o reclamar, otras pedir o solicitar, otras disculparse, otras ofrecer productos, otras amenazar y otras informar (Álvarez, 1997; Dubsky, 1984; Fens-De-Zeeuw, 2008; Gómez de Enterría 1990, 1998 y 2003; Van Hooft, 2004). Por ello, es habitual que las cartas presenten: 1) uso del plural de modestia o, en los casos en los que el emisor/remitente desea personalizar la carta por alguna razón (disculparse, contar algún suceso o preocupación personal), uso de la primera persona

${ }^{14}$ Comparten rasgos, por ejemplo, con el corpus de 15 documentos comerciales del Archivo Garagorri (Madrid) sobre la actividad mercantil desarrollada por el financiero del mismo nombre entre 1850 y 1900 (Gómez de Enterría, 1998) y con el corpus de 250 cartas escritas en México entre 1852 y 1875 que analizó Gómez de Enterría (2003). 
de singular ${ }^{15}$; 2) para el receptor/destinatario, y como suele ser habitual en estos escritos, siempre se utiliza la forma de tratamiento cortés usted, propia del «style élevé» como dice Contamine de Latour; 3) empleo, justificado por la cortesía, del imperativo, del subjuntivo, del futuro de indicativo o de interrogaciones para la expresión de órdenes directas, pues sírvanse, agradeceremos o quisiéramos se usan como estrategias para mitigar la contrariedad o disgusto que pudiera causar la acción que se pide, si bien la cortesía desaparece cuando hay que negar, exigir o defender el negocio, momentos en que aparecen las perífrasis de modalidad deóntica, personal o radical y los verbos volitivos ${ }^{16}$; 4) aunque no suele haber lugar para la expresión de sentimientos en estas cartas, en ocasiones es necesario recurrir a verbos de afección psíquica o psicológicos como atenuantes para manifestar disculpas o negativas (tememos que no nos sea posible aceptar las condiciones; tememos no poder estar en París durante este mes; sentimos el disgusto que esto puede haberles causado); 5) presencia del condicional de probabilidad, del condicional de cortesía o atenuación y del condicional de deseo ${ }^{17}$; 6) referencias al momento en que se producen las transacciones económicas, con diferentes formas de llamar a la carta o misiva recibida, para así evitar errores y confusiones en pedidos o devoluciones: su estimada del 24 del corriente, su apreciable del 7 del corriente, hemos recibido su grata de ayer.

Las cartas comerciales son, pues, textos en los que destacan las estructuras lingüísticas y pragmáticas «indispensable para asegurarse el éxito en el mundo de los negocios y adquieren capital importancia para

${ }^{15}$ Es lo que ocurre, por ejemplo, en la «Lettre promettant de s'occuper d'une commande reçue»: «Acabo de llegar a mi despacho y encuentro la nota que ha dejado su criado. Siento no haberme encontrado aquí para dar inmediatamente la respuesta pedida; pero mañana tendrá V. las muestras con los precios, para que pueda enseñarlas al comprador que V. espera. Tengo unas 4 docenas de cadenas en almacén y puedo tener tantas cuantas deseé a las 48 horas de haber recibido el pedido [...]» (39).

${ }^{16}$ Como en No podemos hacer más que lo que les hemos dicho; Pueden Vv. contar con que el sábado les serán enviadas; Los precios deben ser bajos; No podemos obtener ahora ese precio; El dinero deberá sernos remitido directamente por los clientes. En este sentido y cuando se trata de defender el negocio y su buen nombre, se ponen en funcionamiento todas las herramientas y estrategias lingüísticas y discursivas para conseguirlo.

${ }^{17}$ Ejemplos: Si nos fuera posible aceptarlas con una rebaja, lo haríamos con gusto; Lo que desearíamos son artículos brillantes, que sallen a la vista, a bajos precios, y si los modelos gustan, podremos encargarles grandes cantidades; Les agradeceríamos nos diesen los últimos precios; Desearía saber si V. puede hacerlo al mismo precio; Sus pedidos serían servidos más fácilmente si los hiciesen en español. 
lograr el objetivo de la comunicación empresarial» (Gómez de Enterría, 1998: 388). Pero estas cartas comerciales y las lecciones gramaticales no son suficientes para dominar el español comercial, por lo que los autores del método se ven obligados en muchos casos a incluir notas a pie de página con especificaciones para los lectores franceses sobre la traducción y uso de determinadas formas; así, por ejemplo, señalan que «le futur de subjonctif traduit le présent de l'indicatif précédé de la conjunction si» (16), que «tengo que, suivi d'un verbe, se traduit par je dois, ou j'ai à, ou il faut que» (28), que «lorsque lo complément d'un verbe à l'infinitif est un pronom, il se met après le verbe, en ne formant qu'un seul mot [decírnoslo]»(28), que «le coffre-fort peut se rendre aussi par cofrefuerte; les deux mots existent dans le catalogue des commerçants hispano-américains» (76) o que «les verbes en -zarchangent le $z$ en $c$ devant un e» $(67)^{18}$. Las notas se convierten así en un recurso válido para el aprendizaje de una segunda lengua, pues el aprendiz, gracias a ellas, ve completada su formación lingüística al encontrar en un breve volumen una recopilación de modelos de escritura epistolar comentada en sus puntos más problemáticos o confusos.

Finalmente, los diálogos, materiales didácticos desde la Antigüedad clásica utilizados como ejercicios de traducción (Satorre Grau, 2001), constituyen breves conversaciones que, bajo los títulos "dialogues», "conversations», "phraséologie» o «expressions commerciales», tratan de simular la realidad comercial, lo que debía resultar muy útil para el aprendizaje de esta lengua de especialidad.

${ }^{18}$ La utilización de las notas a pie tampoco es original en este tipo de textos: unos años antes, en 1878, Giovanni B. Melzi (1844-1911), colaborador de Pierre Larousse en el Grand dictionnaire universel du siècle $X I X$ (1864-1876), las había empleado abundantemente en su colección de manuales de correspondencia comercial (en francés, en español, en italiano, en inglés y en alemán). Estas notas, muy diferentes tanto en extensión como en contenido y dificultad, se ocupan, fundamentalmente, de dos aspectos: gramática y léxico. Las primeras, esencialmente descriptivas, utilizan una metodología comparativa para señalar las diferencias entre las dos lenguas en los usos, formas y funciones de las diferentes categorías gramaticales, que son tratadas, tal y como muestran los conceptos y la terminología empleados, siguiendo el modelo tradicional. Las segundas, por su parte, se utilizan para ofrecer traducciones o equivalencias entre las dos lenguas y, en ocasiones, también para introducir matices de significado o diferentes sentidos (García Aranda, 2019). 
Se trata, en suma, de un «méthode pratique» que compendia los contenidos necesarios para desenvolverse en la comunicación comercial, objetivo con que fue redactado y elaborado.

\subsubsection{Léxico}

Junto a la gramática y las prácticas de traducción, el texto se ocupa en sus páginas del léxico. Este puede aparecer o bien dentro de las frases, o bien en notas a pie de página, o bien en el vocabulario final.

Aunque al comienzo del manual Contamine de Latour nos advierte que «les vocabulaires placés à la fin de l'ouvrage contiennent tous les mots employés» (13), lo cierto es que, para facilitar la comprensión de las traducciones y evitar la demora y las dificultades en la consulta del repertorio lexicográfico de las páginas finales, se ve en la necesidad de incluir entre paréntesis algunos equivalentes o sinónimos: aldeas (villages), cliente (parroquiano), al día siguiente (lendemain), Pascuas (Pâques), ventajosas (avantageuses), licores (spiritueux), poco más o menos (environ), tercipelos (velours), carta certificada (lettre recommandée), a qué atenernos (à quoi nous en tenir), azabache (jais), hasta nueva orden (jusqu'à nouvel ordre), todo hace creer (il y a lieu de le croire)...

Las últimas páginas recogen un «Vocabulaire espagnol-français»y otro francés-español "des termes employés dans cet ouvrage», que combinan, dado el contenido de las cartas comerciales y de los ejemplos de uso, términos generales o del léxico común (agua, abrir, adiós, bueno, charco, ciencia, docena, ejemplar, energía, flor, pensar, pulmón, quizá, sed, tranquilamente) con términos característicos de los intercambios comerciales (abonar, accionista, acreditar en cuenta, bolsa, casa de moneda, cheque, comisionista, contabilidad, defraudar, falsificación, franquear, impuesto, libranza, mercancía, pagaré, sacar de apuros, saldo, valija, venta en pública subasta, viajante), así como voces que nombran los productos -y los materiales de que estaban hechos- con los que se mercadeaba en la centuria (azabache, betún, chocolate, coque, cobre, cuchillería, encajes, esmaltes, especias, fósforo, jabón, licor, oro, perfumes, tejidos, tul, vinagreras, zapatos). No resulta, por ello, extraño que los vocabularios recojan mayoritariamente sustantivos, seguidos de adjetivos, verbos, adverbios, pronombres y conjunciones. 
Los dos repertorios incluyen sencillos artículos lexicográficos que ofrecen los equivalentes en ambas lenguas (sinonímicos simples o complejos) sin información gramatical o semántica alguna ${ }^{19}$ :

\begin{tabular}{|c|c|}
\hline Vocabulaire espagnol-français & Vocabulaire français-espagnol \\
\hline antes, avant, antes de ayer, avant-hier & col, cuello; faux-col, cuello postizo \\
bronce, bronze & endommager, echar a perder, deteriorar \\
ensuite, en seguida, después de, luego \\
fabricación, fabrication & horloge, reloj \\
inundar, inonder & hôtel de voyageurs, fonda, hotel \\
luminoso, a, lumineux, se & Hôtel des Postes, administración de correos, \\
pro, profit, el pro y el contra, le pour et le contre & casa de correos \\
quebrar, briser, faire faillite & voleur, ladrón \\
yerno, gendre &
\end{tabular}

TABLA 1. Equivalentes sin información gramatical o semántica

En algunos casos, los equivalentes en la otra lengua incluyen una pseudefinición o descripción para facilitar la comprensión de la traducción; es lo que ocurre, por ejemplo, con «inaudible, inaudible, que l'on ne peut entendre», "sedería, soierie, boutique de soierie», "torno, tour, mouvement circulaire», «vellón, toison, flocon de laine», «japonneries, artículos del Japón, japonerías» o «papelerie, papelería, almacén de papel».

En cinco artículos lexicográficos, Contamine de Latour introduce una marca de transición semántica, au figuré: "apurar, purifier, épurer, au figuré, s'affligen», "araña, araignée; au figuré, lustre d'éclairage», "calavera, tête de mort, au fig., cerveau brûlé», "pecho, poitrine; au figuré, coun» y "arrêter, parar, prender, (au figuré, fijar, clavar)».

Pero la simplicidad y sencillez del artículo lexicográfico obligan, en algunas ocasiones, a utilizar los paréntesis para incluir información adicional de diferente tipo, tanto en la parte español-francés como en la francés-español:

- Sobre la categoría, el género, la forma o la tipología gramaticales, lo que ayudaría a deshacer posibles homonimias, parciales o totales, o a evitar equívocos por la no coincidencia entre las dos lenguas:

${ }^{19}$ A veces las entradas dobles son solo variantes ortográficas: vagón ou wagón, wagon; yerba, hierba, herbe. 


\begin{tabular}{|c|c|}
\hline Vocabulaire espagnol-français & Vocabulaire français-espagnol \\
\hline diente (m.), dent & agrafe, corchete (m.), presilla (f.) \\
lo (art. neut. inv.), le & arriver (unip.), acontecer, suceder \\
medias (subst. f.), bas (les) & charrette, carreta, carretón (m.) \\
nadie (pronom.), personne & fort, e, fuerte (inv.) \\
nueve, neuf(adj. num.) & physique (subst. f.), física \\
pleno, a (adj.), plein & télégramme, telegrama (f.) \\
vuelta (f.), un tour & tendre (adj.), tierno, a \\
\hline
\end{tabular}

TABLA 2. Información gramatical

\begin{tabular}{|c|c|}
\hline $\begin{array}{c}\text { Vocabulaire } \\
\text { espagnol-français }\end{array}$ & Vocabulaire français-espagnol \\
\hline $\begin{array}{c}\text { deber, (subst. m.) devoir } \neq \text { de- } \\
\text { ber, devoir } \\
\text { si (conj.), si, en cas que } \neq \text { si } \\
\text { (adv.), oui }\end{array}$ & $\begin{array}{l}\text { le, la, les (art.), el, la, los, las } \neq \text { le, la, les (pron.), le, } \\
\text { la, lo, los, las } \\
\text { pouvoir (verbe), poder } \neq \text { pouvoir (subst. m.), el poder } \\
\text { propre (subst.), propio } \neq \text { propre (adj.), limpio, a } \\
\text { y (adv.), alli, allá, en aquel lugar } \neq \text { y (pron.), en él, } \\
\text { á él, á ello, á esto, de eso, etc. }\end{array}$ \\
\hline
\end{tabular}

TABLA 3. Información gramatical para deshacer homónimos

\begin{tabular}{|c|c|}
\hline Vocabulaire espagnol-français & Vocabulaire français-espagnol \\
\hline asegurar (se), assurer, s'assurer & abonner (s'), abonar, suscribirse \\
demorar, attarder (s') & asseoir (s'), sentar, sentarse \\
dirigir (se), diriger, s'adresser & assurer (s'), asegurar, asegurarse \\
quejar (se), plaindre (se) & écrier (s'), exclamar \\
sentar (se), asseoir, s'asseoir & promener (se), pasearse \\
vestir (se), se vêtir, s'habiller & presser (se), apresurar, despacharse, darse \\
& prisa \\
& rendre compte (se), hacerse cargo \\
& tromper (se), engañarse, equivocarse \\
\hline
\end{tabular}

TABLA 4. Información gramatical en los verbos (usos pronominales) 
- Para indicar, en el caso de los participios, el infinitivo del verbo al que pertenecen: dorado (dorar); dorer; indispuesto (indisponer), indisposé; instruido (instruir), instruit.

- Para indicar, en el caso de las conjunciones coordinantes, las variantes formales: y (é), et; ú (ó), ou.

- Precisiones en las voces polisémicas para delimitar usos o acepciones, que pueden aparecer en uno de los dos términos o en los dos (como ocurre en el segundo repertorio):

\begin{tabular}{|c|c|}
\hline Vocabulaire espagnol-français & Vocabulaire français-espagnol \\
\hline bodega, cave, cale (de navire) & boite (aux lettres), buzón \\
carta, lettre (correspondance) & bureau (meuble), escritorio \\
certificar, certifier, charger (en parlant d'une lettre) & crêpé(tissu), rizo, rizado \\
cualidad, qualité (en parlant d'une personne) & garçon (célibataire), soltero \\
oro, or (métal) & lettre (caractère), letra \\
yarda (vara), aune espagnol & or (métal), oro \\
& mine (figure), semblante, traza \\
& remise (pour voiture), cochera \\
& timbre (sonnerie), timbre \\
\hline
\end{tabular}

TABLA 5. Información semántica entre paréntesis en algunas voces (polisemia)

\begin{tabular}{|c|}
\hline Vocabulaire français-espagnol \\
\hline argent (métal), plata $\neq$ argent (monnaie), dinero \\
bière (boisson), cerveza $\neq$ bière (cercueil), ataúd, féretro \\
bois (forêt), bosque $\neq$ bois (de construction), madera \\
clef, llaue $\neq$ clef (d'une méthode), clave \\
dé (à coudre), dedal $\neq$ dé (à jouer), dado \\
huile (comestible), aceite $\neq$ huile (pour peindre), óleo \\
peau (d'une personne), cutis $\neq$ peau (tannée), piel $\neq$ peau (brute), pellejo \\
presser (avec une presse), prensar $\neq$ presser (se), apresurar, despacharse, darse prisa \\
qualité (d'une chose), calidad $\neq$ qualité (d'une personne), cualidad \\
saisir (prendre), coger, agarrar $\neq$ saisir (faire une saisie), embargar
\end{tabular}

TABLA 6. Información semántica de las dos voces (polisemia) 
- Para proporcionar información sobre la construcción sintáctica (valencias, argumentos) o combinatoria de las voces, lo que ocurre, de nuevo, especialmente en la parte francés-español:

\begin{tabular}{|c|c|}
\hline Vocabulaire espagnol-français & Vocabulaire français-espagnol \\
\hline $\begin{array}{l}\text { ayunas (en), à jeun } \\
\text { cabo (al), au bout, à la fin } \\
\text { escaso, a, rare, faire défaut (en } \\
\text { parlant d'une chose) } \\
\text { obstante (no), nonobstant } \\
\text { rededor (al), autour, à l'entour }\end{array}$ & $\begin{array}{c}\text { abord (d'), desde luego } \\
\text { attendant (en), esperando, aguardando } \\
\text { avance (d'), de antemano, anticipadamente } \\
\text { conséquent (par), por consecuencia } \\
\text { outre (en), además de } \\
\text { poursuivre (quelqu'un), perseguir } \\
\text { présent (à), ahora } \\
\text { prier (quelqu'un), rogar } \\
\text { renvoyer (quelque chose), volver a enviar renvoyer } \\
\text { (quelqu'un), despedir }\end{array}$ \\
\hline
\end{tabular}

TABLA 7. Información gramatical

Son, pues, dos recopilaciones del léxico utilizado en la obra sin más pretensión que la de facilitar la traducción de las cartas comerciales y de los ejemplos de uso que aparecen en el manual ${ }^{20}$, por lo que su autor reconoce la necesidad de consultar otros repertorios más amplios y ambiciosos, «le vocabulaire qui est à la fin de l'ouvrage ne suffit pas pour la traduction de ces exercices: il faut consulter un Dictionnaire complet» (116).

${ }^{20}$ Como puede inferirse a partir de los ejemplos de este trabajo, la mayoría del léxico recopilado está ampliamente documentado en la lexicografía del español. Se podrían excluir, no obstante, algunos neologismos decimonónicos como calicot (en Gaspar y Roig1853, Zerolo-1895), estenógrafo (en Dominguez-1853, Gaspar y Roig-1853, Salvá-1879 y en $D R A E-1884$ ), fonógrafo (en Zerolo-1895), inmigración (en Gaspar y Roig-1855 y en $D R A E$ 1869), kilómetro (en Dominguez-1853, Gaspar y Roig-1855 y en $D R A E-1869)$, sucursal (en Gaspar y Roig-1855 y en $D R A E-1869$ ) o telegrafiar ( $D R A E-1884)$, fruto de los adelantos científicos y técnicos de la centuria y que muestran cómo las primeras dataciones, dada la influencia de la lengua del país vecino, se encuentran en diccionarios no académicos de influencia o ascendencia francesa, así como la presencia de algunas voces desconocidas para los diccionarios por ser calcos o erróneas traducciones del francés (desflagrar, embadurnear, penumbre, portamina, portaplumas, tabletería, calicot, fraudoloso, fraudulente, japonería, pelerina). Cf. Real Academia Española (2001). 


\subsection{El comercio}

L'espagnol commercial dedica, junto al contenido lingüístico y como cabía esperar, varias páginas a contenido comercial de muy diverso tipo y extensión que ponen de manifiesto el deseo de autor y editor de ofrecer un manual práctico, sencillo, útil y actualizado, ya que «jusqu'à ce jour il manquait, malheureusement, à l'enseignement de l'espagnol une méthode commerciale et technique permettant aux commerçants, aux industriels et aux agriculteurs de se servir de la langue en peu de temps» (5).

En ellas se recoge información sobre la moneda española, sus tipos y sus equivalencias con la francesa; un diálogo sobre manufacturas en que un preceptor explica a su discípulo, a partir de la afirmación de que «la riqueza y la prosperidad de Francia eran debidas principalmente a la importancia y a la variedad de sus manufacturas» (117), qué es una manufactura, qué países las tienen, algunos ejemplos de las más importantes de Francia e Inglaterra o los conocimientos necesarios para crearlas; un alegato en favor del comercio, «el comercio no crea nada; pero es el alma de la industria, como la industria es el alma del Estado» (123-124); una «memoria artificial por la electricidad»; varios fragmentos sobre los hombres que gastan corsés, sobre el fonógrafo de Edison, sobre el mercado de tabaco de Sumatra, sobre los beneficios de las ortigas como alimento para el ganado o sobre la fabricación del negro para la pintura y la impresión. Cierran la obra unas notas geográficas y varios modelos de cartas y documentos («envoi d'un relevé de compte», «un cheque», «póliza de fletamento», «nota de expedición»y «nota de pedidos»).

\section{FUENTES}

Contamine de Latour no oculta las fuentes que le han servido de inspiración para componer L'espagnol commercial, y en las páginas introductorias alaba la labor llevada a cabo por Foulché-Delbosc, para los contenidos lingüísticos, y por Charles Brown y Michel Becker, para los comerciales:

Les livres mis jusqu'à présent entre les mains des élèves et des auditeurs ne contenaient que des phrases banales et sans aucune utilité pour les affaires; ils étaient, en outre, presque tous défectueux tant 
au point de vue du plan qu'à celui de la grammaire, exception faite de la Grammaire espagnole de notre collègue R. Foulché-Delbosc, ouvrage qui à notre avis n'a qu'un défaut, -et encore est-il tout à sa louange- c'est d'être une grammaire savante.

En suivant pour l'espagnol le plan qu'avait conçu M. Brown pour sa méthode anglaise -plan déjà adapté à l'allemand par M. Becker- les éditeurs comblent une lacune et rendent un véritable service aux nombreuses personnes qui en France se livrent au commerce avec l'Amérique espagnole (5).

Se refiere a la Grammaire espagnole del bibliógrafo e hispanista Raymond Foulché-Delbosc (París, Welter, 1888) ${ }^{21}$ y a L'anglais commercial del profesor del Instituto Commercial de París Charles Brown, refundido a partir de la 19. a edición por J. B. Coissac y publicado como Nouvelle méthode de correspondance, expliquant les expressions, termes, formules de commerce, de bourse, de change, etc. y al L'allemand commercial. Nouvelle méthode pratique, enseignant les termes et formules de commerce, de bourse, de change, etc. firmado por Michel Becker, manuales sobre lengua comercial que publicó la editorial Larousse desde las últimas décadas del siglo XIX y hasta bien entrado el siglo XX y que, dado el número de ediciones y de versiones en diferentes lenguas, le debieron reportar importantes beneficios económicos.

Por otro lado, en la página 223 del texto, Contamine de Latour reproduce una lista de «abreviaturas que más comúnmente se usan en español» según la Gramática de la lengua castellana de la Real Academia española (Madrid, Hernando, 1883), texto que durante los siglos XVIII y XIX fue citado y utilizado por la mayoría de autores españoles y extranjeros, en Europa y en América.

Parece, pues, que aunque Contamine de Latour y la editorial Larousse pregonen una gramática sencilla, fueron poco originales: ni el contenido

${ }^{21}$ Foulché-Delbosc fue profesor de las escuelas Say y Colbert de París, así como de la École d'Hautes Études Commerciales, donde pudo coincidir con Contamine de Latour y de ahí las alabanzas hacia su obra. Su Grammaire espagnole se reeditó en 1889. Es, además, autor de un Abrégé de grammaire espagnole (París, Welter, 1892, 1893 y 1894), de unos Exercices espagnols (París, Welter, 1892 y 1893) y, junto a Emmanuel Contamine de Latour, de unos Contes espagnols (París, Société de Publications Internationales, 1889). 
ni el planteamiento de sus manuales son nuevos en la tradición lingüística. Su concepción y sus definiciones de las categorías gramaticales, los ejercicios que los acompañan -temas y versiones- o los breves diálogos habían aparecido con anterioridad.

El mérito de los métodos de la editorial Larousse radica, seguramente, en su practicidad y en su utilidad, pues autor y editor se ocuparon de redactar, a partir de diferentes métodos y de diversas fuentes, "tous les mots, toutes les phrases absolument nécessaires et indispensables au négociant»(6).

\section{CONCLUSIONES}

L'espagnol commercial es una buena muestra de los manuales para fines específicos que se compusieron en el siglo XIX para satisfacer las necesidades que Europa había creado fruto de las transacciones mercantiles con el resto del continente y con las colonias (García Aranda, 2012a, 2012 b y 2019). La rentabilidad económica que estos manuales suponían para autores y editores, sobre todo a partir de la apertura de centros de formación especializados, hizo que se multiplicasen sus publicaciones y sus beneficios.

El contenido de estos textos trataba de aunar, de forma práctica y útil, lengua y comercio, de modo que las descripciones que contienen, las prácticas que plantean o los repertorios lexicográficos que los acompañan, pese a carecer de originalidad, muestran los materiales y los métodos con que se enseñaba español comercial a finales de la centuria, los problemas que ello acarreaba y las soluciones que se proponían.

Los rasgos discursivos que presenta sirven para caracterizar el español con fines específicos de la época (cortesía, fórmulas fosilizadas, fórmulas de tratamiento, actos de habla, marcadores), y para evidenciar su escasa evolución, en muchos casos, pese al paso del tiempo.

Contamine de Latour y la editorial Larousse se sirvieron de textos aparecidos con anterioridad, y los tradujeron o adaptaron para ofrecer un nuevo manual que facilitara el aprendizaje del español comercial, dadas las «grands besoins des commerçants et des industriels» (6), con el 
deseo de que les permitiera «de lire et d'écrire l'espagnol, et même de le parler».

\section{BIBLIOGRAFÍA CITADA}

Álvarez, M. (1997): Tipos de escrito IV: escritos comerciales. Madrid, Arco/Libros.

CAstillo Gómez, A. (2006): Entre la pluma y la pared. Una historia social de la escritura en el Siglo de Oro. Madrid, Akal.

- (2011): «Me alegraré que al recibo de ésta...'. Cuatrocientos años de prácticas epistolares (siglos XVI a XIX)». Manuscrits, 29, págs. 19-50.

Choppin, A. (1992): Les Manuels scolaires: histoire et actualité. Paris, Hachette.

— (dir.) (1995): Les Manuels scolaires en France de 1789 à nos jours: les Manuels d'espagnol. Paris, INRP.

DUBSKY, J. (1984): Aspectos lingüísticos de las cartas comerciales. Madrid, Coloquio.

ESPARZA TORRES, M.A. y NiEdEREHE, H.J. (2015): Bibliografía cronológica de la lingüística, la gramática y la lexicografía del español (BICRES V). Desde el año 1861 hasta el año 1899. Amsterdam-Philadelphia, John Benjamins Publishing.

FEns-DE-ZeEuw, L. (2008): "The letter-writing Manual in the Eighteenth and Nineteenth Centuries: From Polite to Practical». En Dossena, M. y TiekenBoon van Ostade, I. (eds.): Studies in Late Modern English Correspondence. Bern, Peter Lang, págs. 85-98.

FERnÁndez Aguado, J. (1997): Historia de la Escuela de Comercio de Madrid y su influencia en la formación general Española (1850-1970). Madrid, Ilustre Colegio Central de Titulados Mercantiles y Empresariales.

GALLARDO BARBARROJA, M. (2002): «La enseñanza de lenguas extranjeras en el siglo XIX: análisis de algunos métodos publicados en Inglaterra en el aprendizaje de la lengua española». Boletín de la Sociedad Española de Historiografía Lingüística, 3, págs. 89-106.

- (2003): Introducción y desarrollo del español en el sistema universitario inglés durante el siglo XIX. Estudios de Lingüística del Español, vol. 20 (en línea: $<$ http://elies.rediris.es/elies.html> [consulta: 20 de mayo de 2019]).

GARCÍA ARANDA, M.Á. (2012a): «El español de los negocios en el siglo XIX: la Nueva correspondencia comercial francesa-española de José M. Lopes (París, Truchy, 1864)». Bulletin Hispanique, 114, págs. 853-872. 
- (2012b): «Los complementos a los métodos de enseñanza de segundas lenguas: el Manuel de conversations françaises et espagnoles (París, 1835, 1847 y 1862)». Romania, 135, págs. 115-139.

- (2019): «La escritura epistolar y la enseñanza de lenguas: los manuales prácticos de correspondencia comercial de G. B. Melzi (1878)». Romanica Olomucensia, 31.1, págs. 1-20.

GÓMEZ DE ENTERRÍA, J. (1990): Correspondencia comercial en español. Madrid, SGEL.

- (1998): «Rasgos lingüísticos caracterizadores de los escritos comerciales en español durante la segunda mitad del siglo XIX». En Alonso, K. et al. (eds.): El español como lengua extranjera: del pasado al futuro. Actas del VIII Congreso Internacional de ASELE. Alcalá de Henares, Universidad de Alcalá, págs. 387398.

- (2003): "Cortesía y marcadores en un corpus de escritos comerciales del siglo XIX». En Moreno Fernández, F. et al. (eds.): Lengua, variación y contexto: estudios dedicados a Humberto López Morales. Madrid, Arco/Libros, vol. I, págs. 317-327.

Petrucci, A. (2008): Scrivere lettere. Una storia plurimillenaria. Roma-Bari, Laterza.

REAl ACADEMia EsPañola (2001): Nuevo Tesoro Lexicográfico de la Lengua Española (NTLE). Madrid, Espasa Calpe (en línea: http://www.rae.es/recursos/diccionarios/diccionarios-anteriores-1726-1992/nuevo-tesoro-lexicografico [consulta: 20 de mayo de 2019].

SÁnCHez PÉREZ, A. (1992): Historia de la enseñanza del español como lengua extranjera. Madrid, SGEL.

SATORRE GRAU, F.J. (2001): «El diálogo bilingüe de principios del siglo XVII como ejercicio de traducción», en Maquieira Rodríguez, M. et al. (eds.): Actas del II Congreso Internacional de la Sociedad Española de Historiografía Lingüística. Madrid, Arco/Libros, págs. 875-883.

VAN Hooft, A. (dir.) (2004): Textos y discursos de especialidad: El español de los negocios. Amsterdam-New York, Rodopi.

María Ángeles García ARANDA Universidad Complutense de Madrid magaranda@filol.ucm.es 0000-0003-3782-7848 
